\title{
A Brief Analysis of Contribution of Chinese Elements to the Soft Power Enhancement in Chinese Culture
}

\author{
Li Tie \\ School of Foreign Studies, Xi’an University, Xi’an, Shaanxi, China, 710065
}

Keywords: English; Chinese elements; Chinese culture; soft power

\begin{abstract}
In the "going global" strategy for Chinese culture development, a series of traditional Chinese cultural activities and the ones with innovative fusion of western modern elements increasingly brisk up in the world cultural stage. "Chinese English", not "Chinglish", popped into the view of foreigners. As one of the most common languages in the world, English is a necessary skill for social development in the 21st century, especially in the context of global economic integration, and thus more and more Chinese scholars and experts have begun to pay attention to the spread of Chinese culture in the western world, especially in English. The "Chinese English" is a national variant of English with Chinese characteristics, which is a part of English. What's more, Chinese English enriches English. English is incomplete without Chinese English. It is firmly believed that Chinese English will develop with the continuous development of China, and definitely enlarge the influence and the soft power of our overall culture in the world.
\end{abstract}

\section{Introduction}

With the popularization and deepening of English in the whole world, English is gradually transformed into a language symbol with local characteristics. And in recent years, the rise of "Chinese hot", makes the Chinese contact with English broader than ever years. And Chinese itself inherent features more or less have subtle influence on English, which virtually promote the localization process of the English in China. ${ }^{[1]}$ In China, the localization of English mainly manifested in the changes of the elements, especially some of the unique characteristics of the Chinese cultural elements, which overtly symbols of English in China is referred as "China English".

During Hong Kong's colonial period, for the reasons of limited language policy, English is designed as the solely legal official language. Under this background, English, used by the Hong Kong people,is dubbed Chinese Pidgin English, which is early studies language in the social community used by the Hong Kong people English dubbed Chinese Pidgin English. ${ }^{[2]}$ with the development and accumulation of a large number of Chinese elements in it, "China English" which is giving its own certain mysterious and interesting, have attracted many language scholars doing further study until today.

Professor Chuangui Ge in Fudan university is the earliest proponents of the concept of "China English" among a large number of scholars. In view of the "China English", Chuangui Ge proposed they put forward a series of view and understanding of bytes. The emergence of the concept of "China English", sparked a wave of linguistics. Actually, "Chinese English" is formed in the precondition of English language, grammar and vocabulary, which is the perfect fusion of the Chinese nation traditional culture and modern culture. On the basis of English language transformation, it becomes their own special language with the world's recognition of linguistics. The use of "Chinese English" promotes the cross-boundary communication between Chinese and western cultures, and in a certain degree, promotes the real Chinese traditional culture to go abroad.

\section{The Expression of Chinese Elements in English}

The continuously deepening of the Chinese elements in English has sped up the English "localization" process. From the practical point of view, the causes of the phenomenon of "localization" mainly includes the following two aspects: 
On the one hand, life for a long time under the environment of Chinese traditional culture, the Chinese usually learn a new language with Chinese elements of the learning methods for a better understanding and memory, which is an unconscious "extradition" process, especially prominent in learning English grammar or localization phenomenon in everyday speech. ${ }^{[3]}$ On the other hand, in the process of Chinese and English cross-cultural communication, the meaning of some words in Chinese language is too broad, and could not find the corresponding word in English. Also the Chinese with the characteristics of the traditional culture mark can not express the loyal sense, and in order to better understanding English, consciously and purposefully in the Chinese context into the English language, and the phenomena of China English is mainly reflected in English vocabulary semantics in the process of learning English.

\subsection{The embodiment of Chinese contemporary cultural elements in English}

As frequent contacts and fusion of the eastern and western cultures, the national "cultural consciousness" is gradually awakening. In the numerous and unique Chinese culture, more and more words have been translated into English with Chinese characteristics, and gradually accepted by the English-speaking countries, which have a great impact on the aspect of syntax, vocabulary and usage, showing the Chinese English characteristics of both international and local adaptability. Words and phrases generally involve all aspects of the national economy, politics and culture, such as one-child Certificate, One country, Two systems, Economic zone (sez) and so on. ${ }^{[4]}$ At the same time, English is the global language of the world, and English is fully developed in global and regional aspects. And at present, our country has entered the new era of socialism with Chinese characteristics. With the deepening of China's opening to the outside, enhancement of the comprehensive national strength and international influence, the popularization of Chinese English is witnessed in our country.

And English expression with Chinese characteristics also has received recognition by English speaking countries, for example, to keep members of the Communist Part of Chm a (CPC)progressive, innovative and forward thinking, building a well - off society in an all - around way and so on. ${ }^{[4]}$ The inclusion of contemporary Chinese culture special English as English will be the international language in China's further popularization, further development of Chinese society and culture, China's international status rise further and gradually popular, with the charm of a kind of special language form reveals the culture with Chinese characteristics.

\subsection{The embodiment of Chinese traditional cultural elements in English}

The Chinese nation has five thousand years of civilization history. For a long time, the Chinese nation has consistently walked in the forefront of the world, created brilliant culture and made an indelible contribution to world culture. The spread of Chinese words with strong characteristics in English speaking countries have not only improved the richness and universality of English language, but also made it easier to "explain China" to the world. The main effect of object ${ }^{[5]}$ in English, "Chinese English" in English vocabulary, the most widely used, but also the most profound, is a large number of "Chinese English" important "birthplace", from the point of view of vocabulary, covering politics, economy, culture, life, study, history, festivals, clothes, art and so on all aspects, such as (1)Chinese traditional festivals: Mid-Autumn Festival(Mid-Autumn Festival), The Spring Festival (Spring Festival), The Lantern Festival (Lantern Festival), Tomb-sweeping Day (Tombsweeping Day) and so on. (2) Cultural and entertainment projects: Peking Opera (Beijing Opera), shadowboxing (Tai Chi), Chinese kungfu (Chinese KongFu), Calligraphy (Calligraphy), Pipa (Lute). (3) Chinese traditional culture: Confucianism (Confucianism), The Book of Songs (Book of Songs); (4) Chinese traditional costumes: Qipao(Qipao), Mao jacket (Chinese tunic suit), HanFu(HanFu);(5) Chinese food: Peking Roast Duck (Peking duck), jiaozi (dumplings), Tang-yuan (dumpling), Zongzi (Zongzi), Chinese date (red dates), Hot Pot (Hot Pot), etc. In addition, the use of Chinese language to communicate often appears in Chinese idioms, such as the country flour is the country and people live in peace (Cathay Pacific Security), bid fare well to the old and usher in the new (New Year), Harmony brings wealth (Peace brings money), hold high hopes for one's child "(Succeed)etc. [6] 


\section{The Positive Significance of Chinese Elements in English to Enhance the Soft Power of Chinese Culture}

On the one hand, to probe into the significance of Chinese elements in English can promote the identity of Chinese nation and realize the function of Chinese discourse. Chinese English as a result of the collision of Western culture with the Chinese nation, is an effective tool to ensure crosscultural communication among Chinese people. This form of language extracted from the elements of a certain country is, to some extent, also the cultural symbol of the country on the world stage. It is happy to find that recognition and affirmation of "Chinese English" in couples of English countries and Chinese English is to exist together with World English. Chinese elements in Chinese English can not only fully demonstrate the actual connotation of Chinese traditional culture, but also make Chinese English more globalized, diversified and integrated English language environment. It is helpful to become the representative of Chinese children's cultural identity, to strengthen the psychological awareness of Chinese English learning and user self-culture. ${ }^{[7]}$

On the other hand, we should promote intercultural communication and disseminate culture with Chinese characteristics. The most obvious manifestation of the application of Chinese English in the process of practical English lies in the vocabulary. With the bilingual code switching from Chinese to English through transliteration and free translation or literal translation, more Chinese are used in English. The process both contributes to the development of world English and the display of Chinese cultural soft power. ${ }^{[8]}$ For example:

Transliterated explanation: Called the Yungang Shiku, the grottoes in Shanxi Province, the relics had survived the rise and fall of dynasties, modern wars and the cultural revolution ... (May 20, 2014). Among them, the term "Yungang Grottoes" uses the transliteration and interpretative translation strategy, which preserves the color of Chinese culture and fills in the cultural cognitive gaps of foreign readers. Other similar examples in The New York Times are related to Chinese-style foods such as Dandanmian (dan dan noodles), Aiwowo(Aiwowo), Ludagunr (road rolling). ${ }^{[9]}$

Complete transliteration: For example, Chengguan, which literally means "city managers", enforce rules that keep streets orderly and traffic flowing smoothly. (May 30, 2014). There are two kinds of translations of urban management in the sentence, the former adopts the form of transliteration, while the latter mainly uses the method of literal translation. It is obvious that the use of transliteration "Chengguan" can enhance the authenticity and vividness of the report and accurately reflect the special occupations in the Chinese environment. The literal "city manager" may make foreigners puzzled, since the first understanding will be linked with the mayor. Consequently, the word runs counter to the true meaning. Complete Literal Translation: In order to achieve the purpose of preserving Chinese cultural images, we use the literal translation strategies for idioms, special snacks and metaphors in Chinese. Such as: a challenge for China's one-child policy, 2-child policy for only-child parent ... "Family planning policy, separate second child policy", Fitness for All ... "fitness" and so on. ${ }^{[10]}$

\section{Conclusion}

To sum up, with the growing Chinese national strength and frequent exchanges with foreign countries, Chinese English as a variant of the English language has gradually taken the stage of the world. We can believe that Chinese English will continue to improve, and its influence will be further enhanced. It is no wonder that Chinese English will become an important tool for international exchange.

\section{Acknowledgement}

A Study on the Soft Power of Shaanxi Local Dialects through Cross-cultural Translation under the Belt and Road Initiative Project Number: 2017K025 


\section{References}

[1] Baiyu Liu, Xiaqing Liu, Xiaoning Han. A study on the English translation of "dragon" from the perspective of cultural soft power [J]. Journal of Mudanjiang College of Education, 2013(15):336338. Shengli Chen. A study of the number of Chinese Loanwords in the Oxford English Dictionary (Oxford English Dictionary) [J]. Journal of Yancheng Teachers College (Humanities \&Social Sciences Edition)2013(01):187-189.

[2] Changyou Wang. Chinese elements in English vocabulary [J]. Chinese journal (education and teaching in foreign languages). 2015(13):207-210.

[3] Xiaoling Jiang. Processing of Chinese cultural translation in American news journals [D]. University of International Business and Economics 2012(02):164-166.

[4] Official book of the fair: an introduction to a Century of progress international exposition, Chicago June 1-November 1,2011. Century of Progress International Exposition.2011.

[5] Ling Jiang. Ten problems in the construction of soft power of Chinese culture -- Based on the comparison of the soft power of Chinese and American culture [J]. Fujian Tribune (The Humanities \& Social Sciences )2012.

[6] Kaisheng Li, Yu Ning. How to realize the soft power of Chinese culture from "endogenous" to "spillover" [J]? Study Monthly. 2012(15):221-224.

[7] Ying Wu, Guijun Ruan. The effect of Chinese culture survey spread among adolescents in the United States in the Confucius school in Pittsburgh area as an example [J]. Academic Exchanges. 2014(09):83-87.

[8] Ximing Zhu. The Chinese image constructed by the New York Times' china-related editorials -a study on the combination of corpus driven [J]. Journal of Yunnan Agricultural University (Social Science). 2012(21):116-118.

[9] Yanxia Wang. Concern and thought: education power in social phenomenon -- from the perspective of micro perspective to enhance the soft power of culture [J]. Forward Position. 2016(04): 48-51. 